\title{
Effects of pumpless extracorporeal lung assist on hemodynamics, gas exchange and inflammatory cascade response during experimental lung injury
}

\author{
ZHIHAI JU $^{1}$, JINHUI MA ${ }^{1}$, CHEN WANG $^{2}$, JIE YU ${ }^{1}$, YERU QIAO ${ }^{1}$ and FEILONG HEI ${ }^{1}$ \\ ${ }^{1}$ Extracorporeal Circulation Center, National Center for Cardiovascular Diseases, Fuwai Hospital, \\ Chinese Academy of Medical Sciences and Peking Union Medical College, Beijing 100037; \\ ${ }^{2}$ Department of Anesthesiology, Beijing Chaoyang Hospital, Beijing 100020, P.R. China
}

Received January 17, 2017; Accepted August 14, 2017

DOI: $10.3892 /$ etm.2017.5656

\begin{abstract}
Pumpless extracorporeal lung assist (pECLA) has been reported to efficiently remove the systemic $\mathrm{CO}_{2}$ production and provide mild to moderate oxygenation, thereby allowing for ventilator settings and modes prioritizing oxygenation and lung protection. However, an adequate bypass flow, the capacity to provide respiratory support and the effect on the inflammatory cascade response and tissue perfusion require further study to be determined. After induction of acute lung injury (ALI) by oleic acid injection, pECLA was implemented in 12 anaesthetized and mechanically ventilated dogs for $48 \mathrm{~h}$. Improved oxygenation [partial oxygen pressure $\left(\mathrm{PaO}_{2}\right)$ and oxygen saturation $\left(\mathrm{SaO}_{2}\right)$ was measured by arterial blood gas analysis, and increased by 29 and 18\%, respectively] and $\mathrm{CO}_{2}$ elimination (partial $\mathrm{CO}_{2}$ pressure decreased by $43.35 \%$ ) were obtained after pECLA implementation. A maximum arterio-venous shunt flow of up to $25 \%$ of the foundational $\mathrm{CO}$ resulted in stable hemodynamics. The pECLA procedure did not elicit any further increase in the concentration of tumor necrosis factor- $\alpha$, interleukin (IL)-6, IL-8 and endothelin-1 compared with that in the group subjected to oleic acid injection only. In addition, the pECLA procedure had no effect on lactate levels and urine production. In conclusion, pECLA is an efficient and promising strategy for providing a mild to moderate oxygenation and adequate decarboxylation, while avoiding excessive inflammatory cascade response and tissue hypoperfusion in an experimental ALI model.
\end{abstract}

Correspondence to: Dr Feilong Hei, Extracorporeal Circulation Center, National Center for Cardiovascular Diseases, Fuwai Hospital, Chinese Academy of Medical Sciences and Peking Union Medical College, 167 Beilishi Road, Xicheng, Beijing 100037, P.R. China

E-mail: heifeilong@126.com

Key words: acute lung injury, pumpless extracorporeal lung assist, hemodynamics, gas exchange, inflammation, hypoperfusion

\section{Introduction}

A specific characteristic of acute lung injury and acute respiratory distress syndrome (ALI/ARDS) is the sudden life-threatening hypoxemia with or without hypercapnia. Multiple organ failure is considered as the leading cause of death in ALI/ARDS. Despite decreases in recent years, the mortality of ALI/ARDS remains unacceptably high, reaching $45 \%$ in patients with severe complications (1-3). For life-threatening forms of respiratory failure with persistent hypoxemia and hypercapnia unresponsive to conventional therapy, a pump-driven extracorporeal membrane oxygenation (ECMO) technique has been employed. It provided sufficient gas exchange and has been used as a rescue therapeutic method in patients suffering severe ALI/ARDS resistant to conventional therapy with mechanical ventilation (4). It facilitates an adaptive gas exchange and spares the lung from high pressure and inspiratory oxygen fraction $\left(\mathrm{FiO}_{2}\right)$ ventilation. The survival rate associated with the procedure is $\sim 66 \%$ in patients with ALI/ARDS (5).

However, ECMO is also associated with certain complications, including hemorrhage (6), hemolysis (7), thrombosis (8) and circuit infection (9), which may contribute to the mortality in patients receiving ECMO therapy (10). In addition, direct circulation of blood across synthetic surfaces evokes a pro-inflammatory response, further exacerbating a disease process that is already associated with the activation of the inflammatory cascade response (11). The lung has a critical role as a site of inflammation during extracorporeal therapy (12). An increasing body of evidence suggested that ECMO treatment caused an evident increase in the plasma concentration of pro-inflammatory cytokines and neutrophil activation (11,13-15). An escalating inflammatory response usually results in severe neurological injury in patients receiving ECMO treatment $(16,17)$.

To minimize those complications mentioned above and simplify the management of ECMO, a novel therapeutic approach using a pumpless extracorporeal lung assist (pECLA) integrating an arteriovenous shunt-driven oxygenator without a blood pump was developed by an interdisciplinary team at the Hospital of Regensburg University 
(Regensburg, Germany) (18). With the use of the pECLA, the cardiac output $(\mathrm{CO})$ partly drives the extracorporeal blood circulation, the management of ECMO is simplified and its complication rate is minimized (19). However, only few studies have reported on the pathophysiological effects of the procedure, particularly on the pECLA-associated inflammatory cascade response. The present study assessed the hemodynamic effects of pECLA with different bypass flow settings on oleic acid-induced ALI in dogs and determined an appropriate pECLA bypass flow. Furthermore, the adequate gas exchange efficiency of pECLA was confirmed. Finally, the present study evaluated the pECLA-associated inflammatory cascade response and tissue perfusion in the experimental model.

\section{Materials and methods}

Animal preparation. The experimental animal procedures of the present study were performed according to the guidelines from Directive 2010/63/EU of the European Parliament on the protection of animals used for scientific purposes. The study was approved by the ethics committee of Fuwai Hospital [CAMS \& PUMC, approval no. 0083-3-16-HX(B)]. A total of 12 male dogs (weight, $21.83 \pm 1.41 \mathrm{~kg}$ ) were anesthetized by intravenous injection of $30 \mathrm{mg} / \mathrm{kg}$ thiopental and maintained with continuous infusion of $1-2 \mathrm{mg} / \mathrm{kg} / \mathrm{h}$ thiopental and $1 \mathrm{mg} / \mathrm{kg} / \mathrm{h}$ pancuronium. Animals were orotracheally intubated and mechanically ventilated in the supine position in a volume-controlled mode with a tidal volume of $10 \mathrm{ml} / \mathrm{kg}$, a respiratory rate of 20 breaths/min, an inspiratory to expiratory time ratio of $1: 2$ and an $\mathrm{FiO}_{2}$ of 0.4 (Servo 900C Ventilator; Siemens AG, Munich, Germany), which was maintained for 1 h. Subsequently, $500 \mathrm{ml}$ lactated Ringer's injection (Baxter Healthcare Co., Ltd., Shanghai, China) was rapidly infused, followed by continuous infusion of $3 \mathrm{ml} / \mathrm{kg} / \mathrm{h}$ to maintain the intravascular volume status. During the experimental procedure, total fluid input was $3,644 \pm 63.49 \mathrm{ml}$ and the core temperature was kept at $38^{\circ} \mathrm{C}$.

Establishment of experimental ALI model. After adjustment of the $\mathrm{PaO}_{2} / \mathrm{FiO}_{2}$ to 1.0 , other parameters remained unchanged. ALI was induced by injecting oleic acid (Sigma-Aldrich; Merck KGaA, Darmstadt, Germany) at $0.08 \mathrm{ml} / \mathrm{kg}$ in $10 \mathrm{ml}$ normal saline through the central venous catheter. Arterial blood gas was measured every 30 min until the $\mathrm{PaO}_{2} / \mathrm{FiO}_{2}$ was $<200 \mathrm{mmHg}$ for at least $1 \mathrm{~h}$. If the diagnostic criteria $\left(\mathrm{PaO}_{2} / \mathrm{FiO}_{2}<200 \mathrm{mmHg}\right)$ were not reached after $90 \mathrm{~min}$, an additional $0.02 \mathrm{ml} / \mathrm{kg}$ of oleic acid was intravenously injected.

Implementation of pECLA and management. After the ALI was induced, an intravenous heparin bolus (100 IU/kg) was given to achieve an activated clotting time of 120-160 sec and then and continuous anticoagulation was performed by maintaining heparin administration at $30 \mathrm{IU} / \mathrm{kg} / \mathrm{h}$. Femoral artery and internal jugular vein cannulation for pECLA (Novalung; Xenios AG, Heilbronn, Germany) were performed with a 13-Fr and a 15-Fr cannula, respectively. Once connected, the blood/gas flow was maintained at 1:3 and the fraction of inspired oxygen was $100 \%$.

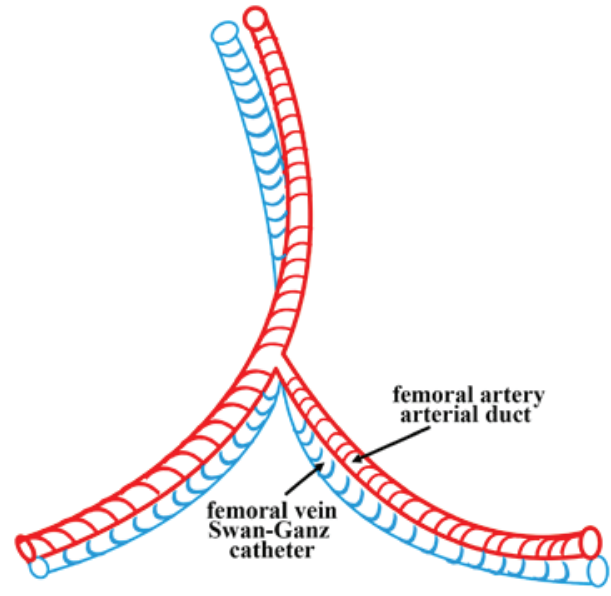

Figure 1. Placement of the Swan-Ganz catheter and the arterial duct. A Swan-Ganz catheter was placed on the other side of the femoral vein and the arterial duct was placed on the other side of the femoral artery.

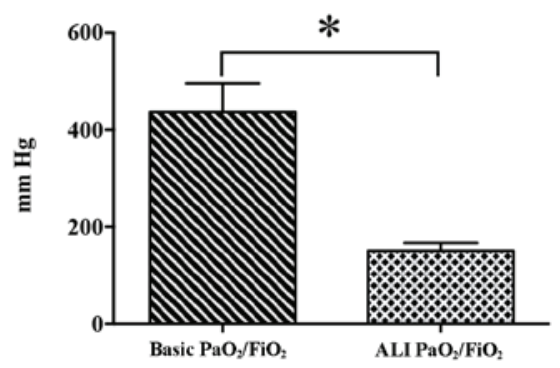

Figure 2. $\mathrm{PaO}_{2} / \mathrm{FiO}_{2}$ decreases following ALI induction. The ALI model was successfully established. Values are expressed as the mean \pm standard deviation $(\mathrm{n}=12)$. ${ }^{*} \mathrm{P}<0.05$. ALI, acute lung injury; $\mathrm{PaO}_{2}$, partial oxygen pressure; $\mathrm{FiO}_{2}$, inspiratory oxygen fraction.

Measurement of parameters. The $\mathrm{CO}$ was defined at $1 \mathrm{~h}$ after the establishment of ALI as a foundational CO. A Swan-Ganz catheter and the arterial duct were placed on the other side of the femoral vein and artery, respectively (Fig. 1). Mean arterial pressure, central venous pressure and pulmonary arterial pressure were directly transduced and recorded. $\mathrm{CO}$ was measured by intrapulmonary artery thermodilution and calculated by a standard monitor with an internal routine validation (IntelliVue MP50; Philips, Amsterdam, the Netherlands) from the mean of three validated bolus injections of $10 \mathrm{ml}$ cold normal saline. The arterial/venous oxygen saturation, arterial/venous partial pressure of oxygen and carbon dioxide were detected by blood gas analysis. Hemodynamic and respiratory parameters were assessed at baseline when ALI was established successfully, and after pECLA implementation for 1, 2, 3, 4, $6,12,24,36$ and $48 \mathrm{~h}$. The levels of serum cytokines [tumor necrosis factor (TNF)- $\alpha$, endothelin, interleukin (IL)-6 and IL-8], as well as lactate, were measured at baseline, when ALI was established and after pECLA support for 12, 24, 36 and $48 \mathrm{~h}$. Urine output was recorded at 24 and $48 \mathrm{~h}$. Blood samples were centrifuged at $350 \mathrm{x}$ g for $15 \mathrm{~min}$ at $4^{\circ} \mathrm{C}$, and the plasma was stored at $-80^{\circ} \mathrm{C}$. Levels of cytokines in plasma were determined by ELISA (TNF- $\alpha$, cat. no. DY1507; IL-6, cat. no. CA6000; IL-8, cat. no. CA8000; all from R\&D 

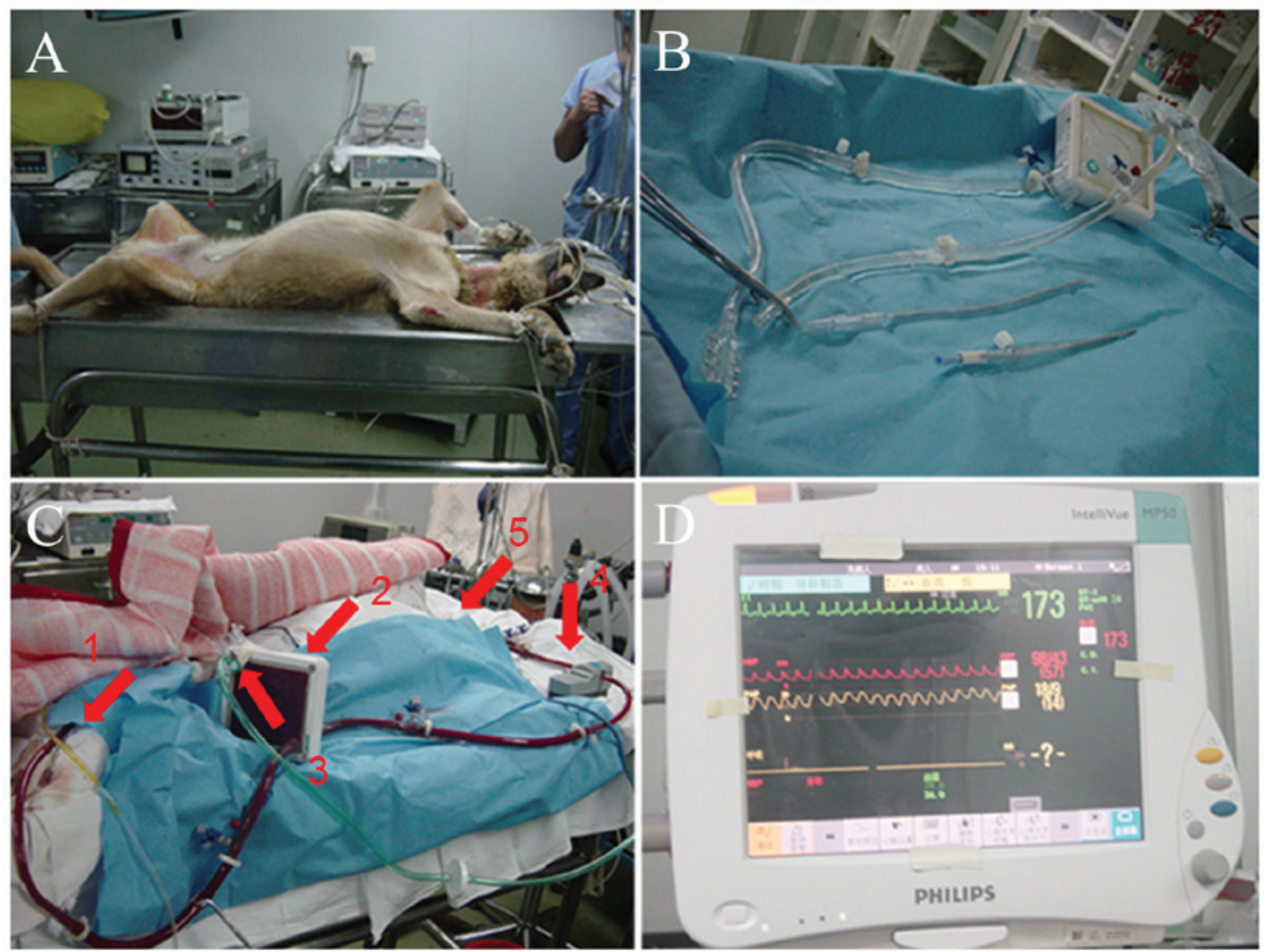

Figure 3. Pumpless extracorporeal lung assist was implemented in an experimental model of acute lung injury. (A) Acute lung injury establishment. (B) pECLA preparation. (C) pECLA implantation. 1, Femoral arterial cannulation; 2, assisted ventilation unit; 3, oxygen inlet; 4, flow monitoring; 5, jugular venous cannulation. (D) Hemodynamic monitoring. pECLA, pumpless extracorporeal lung assist.

Systems, Inc., Minneapolis, MN, USA) and endothelin (cat. no. ab133030; Abcam, Shanghai, China).

Statistical analysis. Values are expressed as the mean \pm standard deviation. All statistical analyses of the data were performed by SPSS 22.0 software (IBM Corp., Armonk, NY, USA). The data were analyzed using Student's t-test and repeated-measures analysis of variance with the least significant differences post hoc test. Statistical significance was accepted at the level of $\mathrm{P}<0.05$.

\section{Results}

Confirmation of ALI model. After the induction of ALI, $\mathrm{PaO}_{2} / \mathrm{FiO}_{2}$ decreased dramatically from $436.71 \pm 11.31$ [95\% confidence interval(CI),399.08-474.34] to $137.86 \pm 84.43 \mathrm{mmHg}$ (95\% CI, 112.54-163.18), which illustrated that the ALI model was successfully established (Fig. 2). Then, the pECLA model was established (Fig. 3).

Hemodynamic parameters. For evaluating the hemodynamic parameters, the experimental animals were randomly divided into two groups. In group A, the shunt flows were gradually increased from 10 to $25 \%$ of the foundational $\mathrm{CO}$ at a $5 \%$ interval and in group B, the shunt flows were gradually decreased from 25 to $10 \%$ of the foundational $\mathrm{CO}$ at a $5 \%$ interval. Each level of shunt flow was maintained for $1 \mathrm{~h}$. The $\mathrm{CO}$, mean arterial pressure (MAP), heart rate (HR), central venous pressure (CVP) and pulmonary arterial pressure (PAP) were recorded as active indices for indicating changes in hemodynamics. As indicated in Fig. 4, the foundational value of the $\mathrm{CO}$ in the groups $\mathrm{A}$ and $\mathrm{B}$ was $3.45 \pm 0.34$ vs. $3.57 \pm 0.46 \mathrm{l} / \mathrm{min}$ prior to oleic acid treatment and $3.08 \pm 0.33$ vs. $3.18 \pm 0.46 \mathrm{l} / \mathrm{min}$ when ALI was established $(\mathrm{P}>0.05)$. During the pECLA period, the $\mathrm{CO}$ varied from 2.4 to $4.3 \mathrm{l} / \mathrm{min}$, and no significant statistical difference was detectable. Maintaining a constant $\mathrm{CO}$ during pECLA may come at the cost of increased ventricular work. Next, the CVP, HR, PAP and MAP, which indirectly reflect the work of the heart, were assessed. Although the blood flow during pECLA ranged from 0.29 to $1.05 \mathrm{l} / \mathrm{min}$ (representing arterio-venous shunt), the CVP, HR and PAP were not different from the baseline value, as presented in Fig. 4. Regarding MAP, a significant difference $(\mathrm{P}=0.048)$ between the two groups after pECLA implementation with a bypass flow of $25 \%$ of the $\mathrm{CO}$ was identified. No vasopressors were necessary to maintain target hemodynamic parameters and no arrhythmia occurred during the pECLA process.

Gas exchange function. To investigate the gas exchange function of pECLA, after hemodynamics evaluation, the shunt flow of all experimental animals was set at $25 \%$ of the $\mathrm{CO}$ and stabilized for $30 \mathrm{~min}$ and the shunt flow was used in further experiments. The $\mathrm{FiO}_{2}$ was then set at 0.21 , and gas exchange was evaluated by clamping the circuit for $60 \mathrm{~min}$ and opening again. The results revealed an evidently improved respiration when pECLA was initiated, with $\mathrm{PaO}_{2}$ and $\mathrm{SaO}_{2}$ increased by $\sim 29$ and $\sim 18 \%$, respectively (from $46.63 \pm 3.86$ to $60.28 \pm 7.07 \mathrm{mmHg}$ and $79 \pm 4$ to $93 \pm 2 \%$, respectively; Fig. 5A). Furthermore, the arterial $\mathrm{PaCO}_{2}$ decreased by $43.35 \%$ (from $35.73 \pm 2.11$ to $20.24 \pm 3.28 \mathrm{mmHg}$ ). The results 

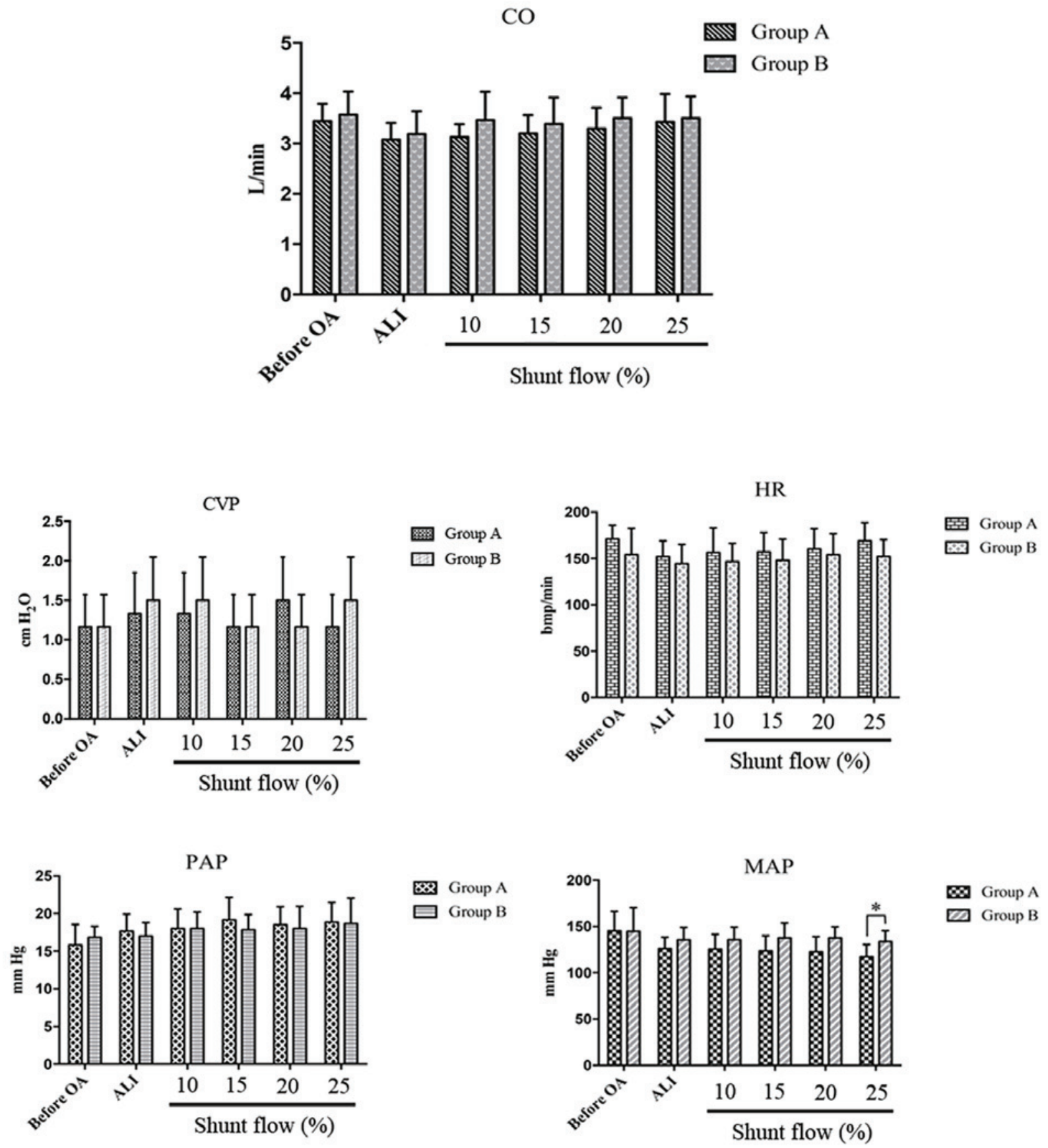

Figure 4. Changes in CO, CVP, HR, PAP and MAP during pECLA. A significant difference in MAP was detected between groups A and B when pECLA support with $25 \%$ of $\mathrm{CO}$ was implemented ("P<0.05). In group A, the shunt flow was gradually increased from 10 to $25 \%$ of the foundational $\mathrm{CO}$ at $5 \%$ intervals and in group B, the shunt flow was gradually decreased from 25 to $10 \%$ of the foundational CO at $5 \%$ intervals. Values are expressed as the mean \pm standard deviation $(\mathrm{n}=6)$. OA, oleic acid injection; ALI, acute lung injury; $\mathrm{CO}$, cardiac output; $\mathrm{CVP}$, central venous pressure; HR, heart rate; PAP, pulmonary arterial pressure; MAP, mean arterial pressure; pECLA, pumpless extracorporeal lung assist.

regarding venous blood gas were similar to those for arterial blood gas. The $\mathrm{PaO}_{2}$ and $\mathrm{SaO}_{2}$ increased by 11.33 and $12.97 \%$, respectively, while the $\mathrm{PaCO}_{2}$ decreased by $47.48 \%$ (Fig. 5B). All of these results revealed that the pECLA is providing a mild to moderately improved oxygenation and $\mathrm{CO}_{2}$ elimination. In the present study, the lung compliance index (CL index) was defined as the tidal volume/peak airway pressure of inspiration for indicating the compliance of the lung when mechanically ventilated. The results displayed in Fig. 5C indicated that the CL index was apparently decreased after ALI was induced. With an adaptive pECLA, the CL index was gradually increased from $14.00 \pm 1.34$ to $15.17 \pm 1.19 \mathrm{ml} / \mathrm{cm} \mathrm{H}_{2} \mathrm{O}$, demonstrating improved lung compliance.

Inflammatory cascade response. A prominent advantage of pECLA is the smaller artificial surface compared with that in ECMO, which may result in a lesser inflammatory response. The next aim of the present study was to determine whether implementation of pECLA was able to avoid an aggravated inflammation. As indicated in Fig. 6, the concentrations of TNF- $\alpha$, IL- 6 , endothelin and IL- 8 at baseline were normal, and after oleic acid injection, the levels 

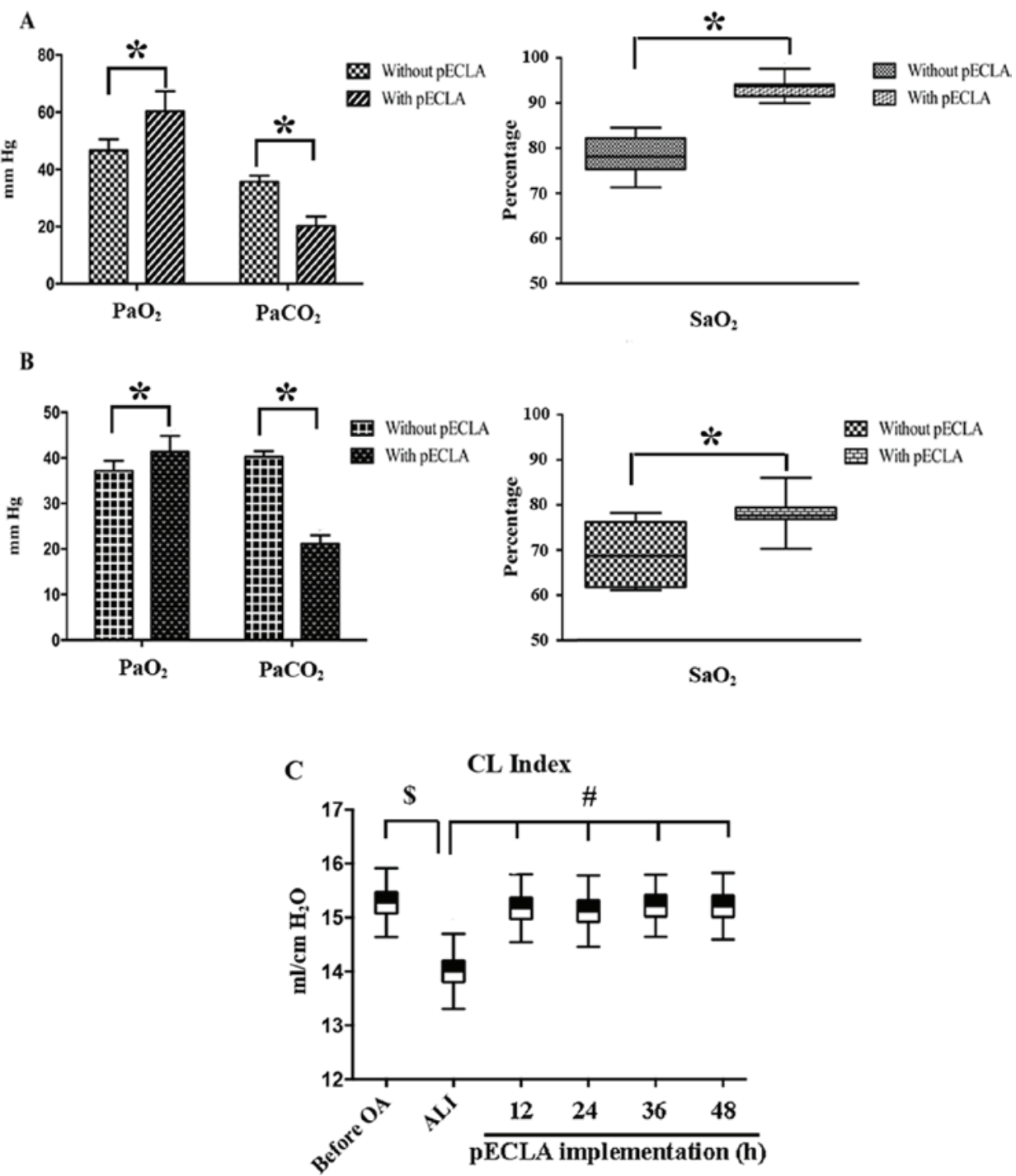

Figure 5. Changes of relevant gas exchange parameters and CL index under pECLA. (A) Improved oxygenation and obvious carbon dioxide elimination after pECLA implementation in the artery. (B) A similar result to that in A was obtained in the vein. (C) The CL index was apparently elevated after ALI was established, and decreased gradually after the implementation of pECLA. Values are expressed as the median, Q1 and Q2, whiskers indicate Q1-1.5 x IQR and $\mathrm{Q} 3+1.5 \mathrm{xIQR}(\mathrm{n}=12) .{ }^{*} \mathrm{P}<0.05 ;{ }^{\$} \mathrm{P}<0.05 ;{ }^{*} \mathrm{P}<0.05$ compared with ALI. OA, oleic acid; ALI, acute lung injury; pECLA, pumpless extracorporeal lung assist; $\mathrm{PaO}_{2}$, partial oxygen pressure; $\mathrm{SaO}_{2}$, saturated oxygen; CL index, lung compliance index (tidal volume/peak airway pressure of inspiration); $\mathrm{Q}$, quartile; $\mathrm{IQR}$, interquartile range.

of TNF- $\alpha$, IL-6, and IL- 8 were significantly increased. However, the pECLA procedure did not elicit any further increase in the concentration of these cytokines. After pECLA implementation, the levels of IL-8 were significantly decreased compared with those immediately after oleic acid injection. In addition, the levels of endothelin-1, a potent endogenous vasoconstrictor, which also acts as a pro-inflammatory cytokine, were not changed during the entire course of the experiment.

Tissue perfusion. The systemic inflammation occurring in ALI/ARDS may impair the physiological regulation of tissue perfusion. As indicated by the results above, establishment of the ALI model induced an evident inflammation with increased levels of TNF- $\alpha$, IL-6 and IL-8. Although pECLA itself did not aggravate the inflammatory response, it was required to evaluate the exact effect of pECLA on tissue perfusion. For this purpose, the lactate levels at the time-points of
pre-pECLA, pECLA implementation for 6,24 and $48 \mathrm{~h}$ and the average urine output during the first and second $24 \mathrm{~h}$ periods were detected to obtain information on the local and systemic perfusion. As displayed in Fig. 7, compared with the baseline value, the lactate levels measured at 6,24 and $48 \mathrm{~h}$ of pECLA were not significantly increased $(\mathrm{P}>0.05)$. Furthermore, the average urine production in the first $24 \mathrm{~h}$ was not different compared with in that during the second $24 \mathrm{~h}(1.53 \pm 0.24$ vs. $1.43 \pm 0.23 \mathrm{ml} / \mathrm{kg} / \mathrm{h} ; \mathrm{P}>0.05)$. Technical failure including oxygenator thrombus or plasma leakage was not encountered during the operation of pECLA. No bleeding or hematoma on the puncture point occurred and no thromboembolism was observed.

\section{Discussion}

The present study was performed to evaluate the effects of pECLA on hemodynamics, gas exchange, inflammatory 

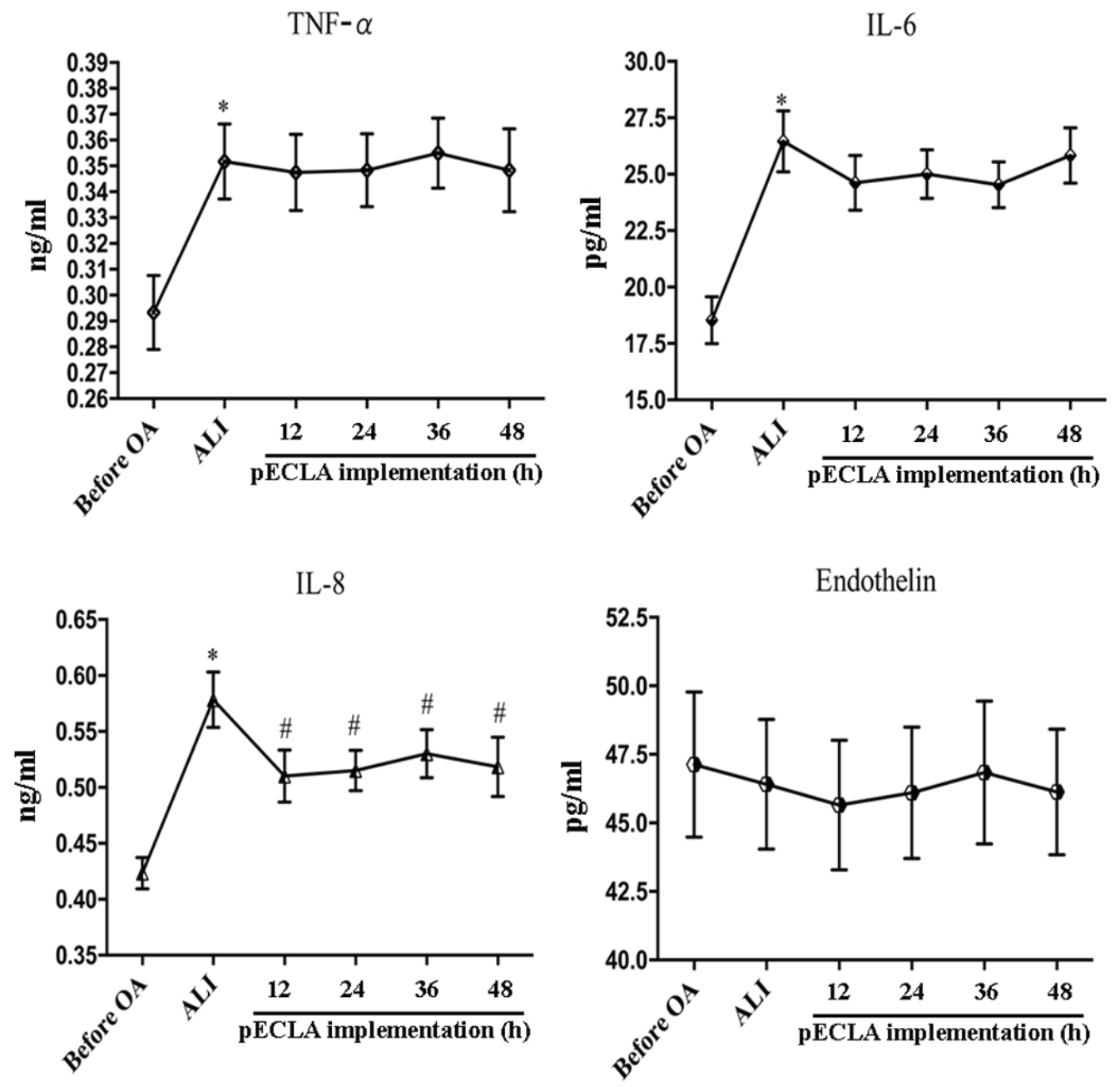

Figure 6. Time course of inflammatory cytokine levels during pECLA. The concentration of TNF- $\alpha$, IL- 6 and IL- 8 was increased after OA injection. After pECLA implementation, the level of IL-8 was significantly decreased. No change was detected in endothelin. Values are expressed as the mean \pm standard deviation $(\mathrm{n}=12)$ " $\mathrm{P}<0.05$ compared with the concentration prior to $\mathrm{OA}$ injection; ${ }^{*} \mathrm{P}<0.05$ compared with the concentration at ALI induction. OA, oleic acid; ALI, acute lung injury; pECLA, pumpless extracorporeal lung assist; TNF, tumor necrosis factor; IL, interleukin.

A

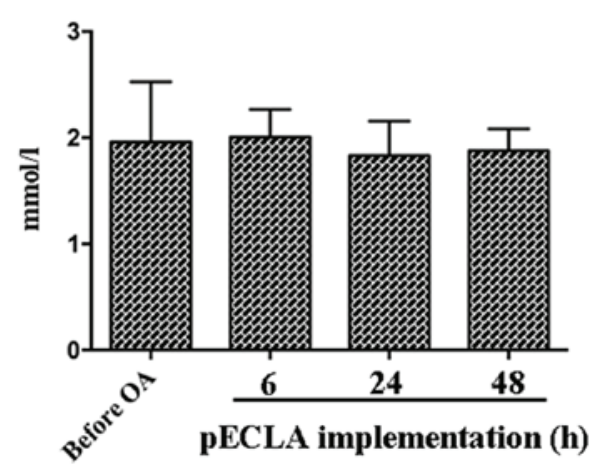

B

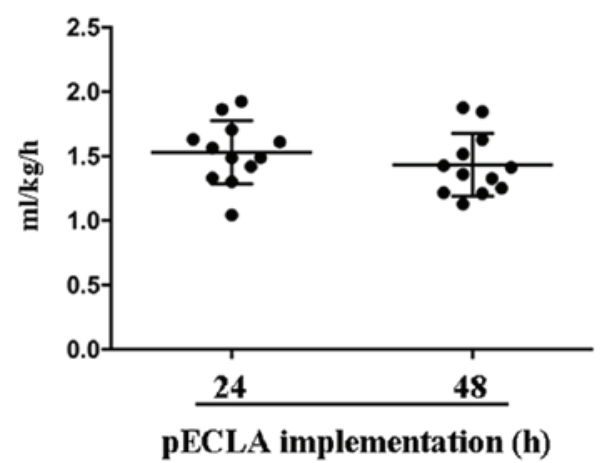

Figure 7. Comparison of lactate value and urine production during pECLA. (A) After implementation of pECLA for 6, 24 and 48 h, the lactate value was not significantly changed compared with the baseline value $(\mathrm{P}>0.05)$. (B) The average urine output was not different between the first and the second $24 \mathrm{~h}$ $(\mathrm{P}>0.05)$. Values are expressed as the mean \pm standard deviation $(\mathrm{n}=12)$. OA, oleic acid; pECLA, pumpless extracorporeal lung assist; LAC, lactate.

response and tissue perfusion in an experimental ALI model. For eliminating confounding factors resulting from preexisting conditions, healthy animals were used to establish an ALI model. Mechanical ventilation has an irreplaceable role in achieving adequate oxygenation and decarboxylation in the treatment of ALI. In certain patients, conventional ventilation must be carried out in a highly invasive manner to achieve adequate gas exchange, resulting in ventilator-induced lung 
injury (VILI) due to side effects including epithelial irritation, inflammation, stress and trauma. pECLA is characterized by a passive arteriovenous shunt flow $(1.0-2.5 \mathrm{l} / \mathrm{min})$ generated by the arterial blood pressure. The use of pECLA allows for adequate $\mathrm{CO}_{2}$ elimination and a mild to moderate oxygenation in patients where conventional ventilation fails. A noteworthy adfvantage of pECLA over ECMO is that lower blood flows are required for removing $\mathrm{CO}_{2}(300-1,500$ vs. $3,000-5,000 \mathrm{ml} / \mathrm{min}$ ). Due to this low amount of blood flow, a relatively small vascular cannula is used, while it is usually slightly larger than that used for continuous venovenous hemofiltration (20). A previous study reported that the use of a small tidal volume combined with pECLA has the potential to further reduce VILI compared with a standard lung protective management strategy in patients with severe ARDS (21). Kreyer et al (22) reported that the pECLA device is effective in reducing $\mathrm{CO}_{2}$, while keeping airway pressures low. In addition, the intubation rate was low in patients receiving noninvasive ventilation (NIV) plus pECLA (12 vs. $33 \%$ in those receiving NIV only) (20).

The present study initially determined the influence of pECLA with different shunt flows on the hemodynamics in an experimental ALI model. To exclude the effect of hypercapnia on changes in hemodynamics, the parameters of the ventilator were adjusted to maintain a normal arterial $\mathrm{PaCO}_{2}$, and it was revealed that a tidal volume of $10 \mathrm{ml} / \mathrm{kg}$ with 20 breaths $/ \mathrm{min}$ achieved an ideal $\mathrm{PaCO}_{2}$ in the present ALI model. The blood flow was then gradually changed while keeping the ventilator setting constant to determine the resultant effects of different shunt flows on hemodynamics parameters. When the shunt flow was altered within the range of $10-25 \%$ of the $\mathrm{CO}$, the hemodynamic parameters remained stable regardless of gradual increases or decreases in blood flow, except for the MAP, which demonstrated a significant difference at a shunt flow of $25 \%$ of the $\mathrm{CO}(\mathrm{P}=0.048)$, and this indicated that an early adaptive shunt flow may be more beneficial for the maintenance of the circulation. The setting of $10 \%$ of the $\mathrm{CO}$ as the minimum bypass flow was used based on the study by Brunston et al (23), who reported that a gradual rise in the systemic $\mathrm{PaCO}_{2}$ was seen at flows of $>500 \mathrm{ml} / \mathrm{min}(\sim 7 \%$ of the CO) in healthy sheep. Again, when the blood flow exceeded $25 \%$ of the $\mathrm{CO}$, vasoactive drugs are usually required (24). The results of the present study revealed that a maximum flow of $25 \%$ of the $\mathrm{CO}$ is recommended, as it does not cause any fluctuation of hemodynamic parameters and does not require vasopressor agent application.

As the $\mathrm{CO}$ drives the extracorporeal blood circulation during pECLA, a membrane oxygenator with a small resistance is indispensable. Significant progress has been made regarding the material characterized by minimized pressure decrease across the membrane and reduced extracorporeal surfaces allowing for near-total carbon dioxide removal and moderate oxygenation with minimal cellular trauma, coagulation alterations and immunologic response (25-29). Thus, the present study further investigated the respiratory effects of pECLA in the experimental model. A moderate oxygenation and high $\mathrm{CO}_{2}$ elimination were achieved during the process. Improved gas exchange after ALI led to a reduction in tidal volume and peak airway pressure, and also caused a visible reduction of the CL index. Hyperdistension may occur despite a low tidal volume ventilation with an airway pressure of
28-30 $\mathrm{cm} \mathrm{H}_{2} \mathrm{O}$ (30). The implementation of pECLA leading to a reduction in $\mathrm{FiO}_{2}$, tidal volume and peak airway pressure may be of benefit after lung injury through unloading the lungs and providing lung-protective settings.

The use of heparin-coated circuits and oxygenators has led to a substantial reduction of inflammatory reactions associated with ECMO. However, McIlwain et al (13) recently implemented ECMO in a neonatal porcine model and observed that the levels of inflammatory cytokines rose rapidly during the first $8 \mathrm{~h}$. Theoretically, pECLA should cause a lesser inflammatory response than ECMO due to the smaller extracorporeal surface. For this purpose, the levels of inflammatory cytokines, including TNF- $\alpha$, IL-6, IL-8 and endothelin-1, were measured in the present study during the process of pECLA. After oleic acid injection, the levels of TNF- $\alpha$, IL-6 and IL- 8 were obviously increased and maintained at a high level compared with the baseline value. Of note, pECLA did not further increase the serum levels of TNF- $\alpha$, IL- 6 and IL-8. This is consistent with previous clinical study, which demonstrated that using pECLA provided complete respiratory support during complex airway reconstructions without inducing cellular trauma or a coagulatory and inflammatory response (29). pECLA decreased the levels of IL-8 compared with those immediately after establishment of ALI, which may be based on various possible mechanisms. The contact of circulatory blood with the surfaces of artificial materials is an important factor for inflammatory activity and pECLA has a smaller surface of synthetic materials compared with ECMO. High shear stress is another important reason causing a high level of inflammatory cytokines, and pECLA, integrating arteriovenous shunt-driven oxygenator without a blood pump, decreases the shear stress of the circuit, resulting in a reduction of plasma cytokines. Increases in inflammatory cytokine levels and the activation of complement and coagulation pathways may lead to endothelial cell injury, microcirculation disturbance and multiple organ dysfunction (11,13,31-33). Above all, pECLA with a smaller artificial surface and low shear stress may minimize the complications of artificial oxygenation. A previous study has demonstrated that hypoxemia obviously induced the expression of the IL-8 gene in endothelial cells in a time-dependent manner (34). Thus, the amelioration of hypoxemia with continuous mechanical ventilation and pECLA support may be attributed to the decrease of IL-8 observed in the present study. Of note, endothelin-1, which is mainly secreted by endothelial cells and is able to induce the inflammatory response, increase superoxide anion production and cytokine secretion, was neither changed by oleic acid injection nor pECLA implementation. While the reason for this finding remains elusive, it is likely that, as a potent endogenous vasoconstrictor, endothelin-1 may be implicated in a feedback regulation of the systemic blood pressure, and as the fluctuation of hemodynamics during pECLA was only slight, endothelin remained stable (35). Certain studies have demonstrated that heparin inhibits endothelin production through various mechanisms (36-38). During pECLA, in order to decrease the high risk of clotting due to a low flow passing through the extracorporeal membrane, full anticoagulation was achieved by heparin injection followed by continuous infusion for maintaining an appropriately activated clotting time, and this may have also inhibited the release of 
endothelin. In general, assessing endothelin for estimating the inflammatory response may be not suitable during pECLA.

The effects of the arteriovenous shunt on local and systemic tissue perfusion remain ambiguous. In the present study, the lactate levels at the side of the arterial cannulation and the average urine production were assessed for revealing the local and systemic perfusion. The results revealed that a maximum shunt flow of $25 \%$ of the CO did not increase the lactate levels or decrease the average urine volume within $48 \mathrm{~h}$. However, in clinical practice, pECLA may result in limb ischemia due to hypoperfusion. The reasons are complex and may be attributed to the severity and duration of the disease, sympathetic activation, catecholamine release, application of vasopressor agents and concomitant diseases. Thus, in clinical practice, careful observation of the effects of lower limb perfusion at the arterial cannulation site is required.

In conclusion, the results of the present study suggested that the pECLA is an efficient and promising strategy for providing mild to moderate oxygenation and adequate decarboxylation, while avoiding an excessive inflammatory cascade response and tissue hypoperfusion in an experimental model of ALI.

\section{References}

1. Phua J, Badia JR, Adhikari NK, Friedrich JO, Fowler RA, Singh JM, Scales DC, Stather DR, Li A, Jones A, et al: Has mortality from acute respiratory distress syndrome decreased over time?: A systematic review. Am J Respir Critic Care Med 179: 220-227, 2009.

2. ARDS Definition Task Force, Ranieri VM, Rubenfeld GD, Thompson BT, Ferguson ND, Caldwell E, Fan E, Camporota L and Slutsky AS: Acute respiratory distress syndrome: The Berlin Definition. Jama 307: 2526-2533, 2012.

3. Ferguson ND, Fan E, Camporota L, Antonelli M, Anzueto A, Beale R, Brochard L, Brower R, Esteban A, Gattinoni L, et al: The Berlin definition of ARDS: An expanded rationale, justification, and supplementary material. Intensive Care Med 38: 1573-1582, 2012.

4. Iwashita Y and Imai H: Extracorporeal lung assist for sepsis and acute respiratory distress syndrome. Cardiovasc Hematol Disord Drug Targets 15: 46-56, 2015.

5. Peek GJ, Mugford M, Tiruvoipati R, Wilson A, Allen E, Thalanany MM, Hibbert CL, Truesdale A, Clemens F, Cooper $\mathrm{N}$, et al: Efficacy and economic assessment of conventional ventilatory support versus extracorporeal membrane oxygenation for severe adult respiratory failure (CESAR): A multicentre randomised controlled trial. Lancet 374: 1351-1363, 2009.

6. Repessé X, Au SM, Bréchot N, Trouillet J-L, Leprince P, Chastre J, Combes A and Luyt CE: Recombinant factor VIIa for uncontrollable bleeding in patients with extracorporeal membrane oxygenation: Report on 15 cases and literature review. Crit Care 17: R55, 2013.

7. Toomasian JM and Bartlett RH: Hemolysis and ECMO pumps in the 21st century. Perfusion 26: 5-6, 2011.

8. Kössel H, Bartsch H, Philippi W, Unger M, Bauer K, Eyrich K, Waldschmidt $\mathrm{J}$ and Versmold HT: Pulmonary embolism and myocardial hypoxia during extracorporeal membrane oxygenation. J Pediatr Surg 34: 485-487, 1999.

9. Sun HY, Ko WJ, Tsai PR, Sun CC, Chang YY, Lee CW and Chen YC: Infections occurring during extracorporeal membrane oxygenation use in adult patients. J Thorac Cardiovasc Surg 140: 1125-1132. e2, 2010.

10. Zangrillo A, Landoni G, Biondi-Zoccai G, Greco M, Greco T, Frati G, Patroniti N, Antonelli M, Pesenti A and Pappalardo F: A meta-analysis of complications and mortality of extracorporeal membrane oxygenation. Crit Care Resusc 15: 172-178, 2013.

11. Fortenberry JD, Bhardwaj V, Niemer P, Cornish JD, Wright JA and Bland L: Neutrophil and cytokine activation with neonatal extracorporeal membrane oxygenation. J Pediatr 128:670-678, 1996.
12. Massoudy P, Zahler S, Becker BF, Braun SL, Barankay A and Meisner H: Evidence for inflammatory responses of the lungs during coronary artery bypass grafting with cardiopulmonary bypass. Chest 119: 31-36, 2001.

13. McIlwain RB, Timpa JG, Kurundkar AR, Holt DW, Kelly DR, Hartman YE, Neel ML, Karnatak RK, Schelonka RL, Anantharamaiah GM, et al: Plasma concentrations of inflammatory cytokines rise rapidly during ECMO-related SIRS due to the release of preformed stores in the intestine. Lab Invest 90: 128-139, 2010.

14. Song J, Palmer K and Sun B: Effects of inhaled nitric oxide and surfactant with extracorporeal life support in recovery phase of septic acute lung injury in piglets. Pulm Pharmacol Ther 23: 78-87, 2010.

15. Graulich J, Walzog B, Marcinkowski M, Bauer K, Kössel H, Fuhrmann G, Bührer C, Gaehtgens P and Versmold HT: Leukocyte and endothelial activation in a laboratory model of extracorporeal membrane oxygenation (ECMO). Pediatr Res 48: 679-684, 2000 .

16. Bembea MM, Savage W, Strouse JJ, Schwartz JM, Graham E, Thompson CB and Everett A: Glial fibrillary acidic protein as a brain injury biomarker in children undergoing extracorporeal membrane oxygenation. Pediatr Crit Care Med 12: 572-579, 2011.

17. Risnes I, Wagner K, Nome T, Sundet K, Jensen J, Hynås IA, Ueland T, Pedersen T and Svennevig JL: Cerebral outcome in adult patients treated with extracorporeal membrane oxygenation. Ann Thorac Surg 81: 1401-1406, 2006.

18. Reng M, Philipp A, Kaiser M, Pfeifer M, Gruene S and Schoelmerich J: Pumpless extracorporeal lung assist and adult respiratory distress syndrome. Lancet 356: 219-220, 2000.

19. Bein T, Weber F, Philipp A, Prasser C, Pfeifer M, Schmid FX, Butz B, Birnbaum D, Taeger K and Schlitt HJ: A new pumpless extracorporeal interventional lung assist in critical hypoxemia/hypercapnia. Crit Care Med 34: 1372-1377, 2006.

20. Del Sorbo L, Pisani L, Filippini C, Fanelli V, Fasano L, Terragni P, Dell'Amore A, Urbino R, Mascia L, Evangelista A, et al: Extracorporeal $\mathrm{Co} 2$ removal in hypercapnic patients at risk of noninvasive ventilation failure: A matched cohort study with historical control. Crit Care Med 43: 120-127, 2015.

21. Bein T, Weber-Carstens S, Goldmann A, Müller T, Staudinger T, Brederlau J, Muellenbach R, Dembinski R, Graf BM, Wewalka $\mathrm{M}$, et al: Lower tidal volume strategy $(\approx 3 \mathrm{ml} / \mathrm{kg})$ combined with extracorporeal $\mathrm{CO} 2$ removal versus 'conventional' protective ventilation $(6 \mathrm{ml} / \mathrm{kg})$ in severe ARDS: The prospective randomized Xtravent-study. Intensive Care Med 39: 847-856, 2013.

22. Kreyer S, Muders T, Luepschen H, Kricklies C, Linden K, Tolba R, Varelmann D, Zinserling J, Putensen C and Wrigge H: Pumpless extracorporeal $\mathrm{CO}(2)$ removal restores normocapnia and is associated with less regional perfusion in experimental acute lung injury. Acta Anaesthesiol Scand 58: 52-60, 2014.

23. Brunston RL Jr, Zwischenberger JB, Tao W, Cardenas VJ Jr, Traber DL and Bidani A: Total arteriovenous CO2 removal: Simplifying extracorporeal support for respiratory failure. Ann Thorac Surg 64: 1599-1605, 1997.

24. Chapman J, Adams M and Geha AS: Hemodynamic response to pumpless extracorporeal membrane oxygenation. J Thorac Cardiovasc Surg 99: 741-750, 1990.

25. Hommel M, Deja M, von Dossow V, Diemel K, Heidenhain C, Spies $\mathrm{C}$ and Weber-Carstens S: Bronchial fistulae in ARDS patients: Management with an extracorporeal lung assist device. Eur Respir J 32: 1652-1655, 2008.

26. Johnson P, Fröhlich S and Westbrook A: Use of extracorporeal membrane lung assist device (Novalung) in H1N1 patients. J Card Surg 26: 449-452, 2011.

27. Iglesias M, Martinez E, Badia JR and Macchiarini P: Extrapulmonary ventilation for unresponsive severe acute respiratory distress syndrome after pulmonary resection. Ann Thorac Surg 85: 237-244, 2008.

28. Iglesias M, Jungebluth P, Petit C, Matute MP, Rovira I, Martínez E, Catalan M, Ramirez J and Macchiarini P: Extracorporeal lung membrane provides better lung protection than conventional treatment for severe postpneumonectomy noncardiogenic acute respiratory distress syndrome. J Thorac Cardiovasc Surg 135: 1362-1371, 2008

29. Sanchez-Lorente D, Iglesias M, Rodríguez A, Jungebluth P and Macchiarini P: The pumpless extracorporeal lung membrane provides complete respiratory support during complex airway reconstructions without inducing cellular trauma or a coagulatory and inflammatory response. J Thorac Cardiovasc Surg 144: 425-430, 2012. 
30. Terragni PP, Rosboch G, Tealdi A, Corno E, Menaldo E, Davini O, Gandini G, Herrmann P, Mascia L, Quintel M, et al: Tidal hyperinflation during low tidal volume ventilation in acute respiratory distress syndrome. Am J Respir Crit Care Med 175: 160-166, 2007.

31. Underwood M, Pearson J, Waggoner J, Lunec J, Firmin R and Elliot M: Changes in 'inflammatory' mediators and total body water during extra-corporeal membrane oxygenation (ECMO). A preliminary study. Int J Artif Organs 18: 627-632, 1995.

32. Mildner RJ, Taub N, Vyas JR, Killer HM, Firmin RK, Field DJ and Kotecha S: Cytokine imbalance in infants receiving extracorporeal membrane oxygenation for respiratory failure. Biol Neonate 88: 321-327, 2005.

33. Kelly RE Jr, Phillips JD, Foglia RP, Bjerke HS, Barcliff LT, Petrus L and Hall TR: Pulmonary edema and fluid mobilization as determinants of the duration of ECMO support. J Pediatr Surg 26: 1016-1022, 1991

34. Karakurum M, Shreeniwas R, Chen J, Pinsky D, Yan SD, Anderson M, Sunouchi K, Major J, Hamilton T, Kuwabara K, et al: Hypoxic induction of interleukin-8 gene expression in human endothelial cells. J Clin Invest 93: 1564-1570, 1994.

35. Iglarz M, Steiner P, Wanner D, Rey M, Hess P and Clozel M: Vascular Effects of endothelin receptor antagonists depends on their selectivity for ETA Versus ETB receptors and on the functionality of endothelial ETB receptors. J Cardiovasc Pharmacol 66: 332-337, 2015.
36. Yokokawa K, Tahara H, Kohno M, Mandal A, Yanagisawa M and Takeda T: Heparin regulates endothelin production through endothelium-derived nitric oxide in human endothelial cells. J Clin Invest 92: 2080-2085, 1993.

37. Kowalczyk A, Kleniewska P, Kolodziejczyk M, Skibska B and Goraca A: The role of endothelin-1 and endothelin receptor antagonists in inflammatory response and sepsis. Arch Immunol Ther Exp (Warsz) 63: 41-52, 2015.

38. Simard JM, Tosun C, Ivanova S, Kurland DB, Hong C, Radecki L, Gisriel C, Mehta R, Schreibman D and Gerzanich V: Heparin reduces neuroinflammation and transsynaptic neuronal apoptosis in a model of subarachnoid hemorrhage. Transl Stroke Res 3 (Suppl 1): S155-S165, 2012.

This work is licensed under a Creative Commons Attribution-NonCommercial-NoDerivatives 4.0 International (CC BY-NC-ND 4.0) License. 